\title{
A «VELHA» E A «NOVA» HISTÓRIA EMPRESARIAL EM PORTUGAL, 1924-1994. TENDÊNCIAS E RESULTADOS*
}

\author{
José Amado Mendes**
}

\begin{abstract}
A história, na "conquista" de novos assuntos, tem vindo a descobrir as potencialidades da empresa como objecto de estudo. Em Portugal, desde os inícios de Oitocentos que começou a dedicar-se alguma atenção à história das empresas. Marco importante, na evolução deste ramo historiográfico, foi a comemoração do centenário da Vista Alegre, em 1924, e os trabalhos então publicados.

Posteriormente, a referida historiografia enquadra-se em dois paradigmas diferentes. Assim, até aos anos 1960, pode falar-se de "velha" história empresarial, feita essencialmente por amadores com intuitos comemoracionistas e, não raro, laudatórios. A partir da década de 70, por sua vez, começou a emergir a "nova" história das empresas, com a participação mais frequente de investigadores especializados e o recurso a novos tipos de fontes. Além do mais, também os momentos menos "felizes" - $e$ não apenas os de inequivoco sucesso - começaram a ser objecto de análise.
\end{abstract}

\section{INTRODUÇÃO}

A adjectivação da história está na moda. Por isso, história, sem mais, tornou-se um conceito excessivamente lato, podendo abarcar tudo, o que lhe rouba operacionalidade. Daí o falarmos em história por especialidades, tais como,

** Faculdade de Letras da Universidade de Coimbra; Pólo de Viseu do Centro Regional das Beiras da Universidade Católica Portuguesa; investigador do Centro de Estudos Interdisciplinares do Século XX (CEIS 20). 
entre muitas outras: história política, história económica, histórica social, história da ciência e da tecnologia, história da banca, história do quotidiano, história da vida privada, história da cultura e das mentalidades, etc. Ou, noutra perspectiva, de história das múltiplas ciências, de entre as quais: medicina, fisica, biologia, botânica, matemática e engenharia. Mas, segundo um outro ponto de vista, a «classificação» da história pode ainda fazer-se tendo em vista as concepções teórico-metodológicas que lhes estão subjacentes e que, ao invés das designações anteriores - cuja distinção se fundamenta no objecto de estudo -, têm obviamente a «marca» distintiva do historiador ou, mais genericamente, do cientista social (que pode ser sociólogo, economista, especialista em ciência política, etc.). Assim, são conhecidas expressões como as seguintes: história narrativa e história quantitativa; história descritiva ou história-problema; história-batalha, história cronológica ou história serial. Como se tudo isto não fosse algo já complexo - sobretudo quando se procura definir e caracterizar cada uma das referidas modalidades da ciência histórica (ou, se se preferir, do saber histórico) -, a verdadeira revolução historiográfica, registada particularmente no último meio século, induziu o aparecimento de novas expressões, a saber: nova história, por oposição à velha ou à história tradicional, nova história económica ou até, mais recentemente, «nova nova» história ou história pós-moderna. Para me cingir apenas a estas últimas designações, o seu uso tem sido adoptado mais por motivos pragmáticos do que científicos. $\mathrm{O}$ historiador - ou o que se dedica ao estudo da historiografia -, ao ter a sensação que está perante um novo paradigma científico (T. S. Kuhn), procura situar a sua «nova ciência» face à praticada pelos que o precederam, apelidando-a de nova. Em certos casos, trata-se mesmo de um novo tipo de história, podendo, por isso, classificar-se de nova. Noutros, porém, a novidade é diminuta e a designação pode induzir em erro. Recorde-se, a propósito, a interessantíssima - ainda que polémica - obra de Gertrude Himmelfarb, The New History and the Old. Após aludir à historiografia de alguns precursores da nova história (dos inícios do século XX), comenta: «Deste modo, a nova história é mais velha do que se podia pensar, enquanto a velha não está ainda assim tão antiquada»!.

Com o uso das designações de nova e/ou velha pretende-se, obviamente, sublinhar a novidade trazida por aquela, esquecendo-se muitas vezes o legado da velha história, que vai sendo, em grande parte, introduzido sucessivamente nas correntes historiográficas seguintes. Trata-se, pois, de um fenómeno semelhante ao das revoluções, cujas consequências são, frequentemente, exageradas pelos respectivos protagonistas, devido ao seu fervor revolucionário, mais receptivos ao resultado da sua acção do que ao que persiste do contexto anterior.

Em suma: independentemente das críticas que possam fazer-se às expressões anteriormente indicadas, elas revelam-se funcionais, desde que entre 
o velho e o novo não se sublinhem só as rupturas, mas se tenha em vista que em história, como geralmente nos outros ramos do conhecimento, o desenvolvimento científico, salvo raras excepções, se faz de modo cumulativo. No que concerne à nova e à velha história empresarial, o que se pretende - por analogia com o que se passa com a história, em geral - é chamar a atenção para a existência como que de dois modelos, já susceptiveis de ser detectados na ainda escassa história empresarial portuguesa. Veremos, entretanto, quais as principais distinções entre uma e outra, procurando também averiguar os condicionalismos que terão possibilitado a prática daqueles dois tipos de história.

\section{ANTECEDENTES OITOCENTISTAS DA HISTÓRIA EMPRESARIAL EM PORTUGAL}

Os primórdios da história empresarial, em Portugal, remontam, pelo menos, aos inícios do século XIX. Estava-se nos finais do Antigo Regime, tendo-se então registado um certo desenvolvimento das chamadas manufacturas (têxtil, vidro, cerâmica, etc.), num contexto propício ao take-off da industrialização. Entretanto, este viria a ser adiado, devido, entre outros factores, à concorrência britânica e à instabilidade provocada pelas invasões francesas (1807-1810).

Neste contexto, sumariamente descrito, destacou-se José Acúrsio das Neves (1766-1834), estudioso, investigador e um apologista da industrialização. Por exemplo, num documento de 1817 sublinhava:

«Contudo, a sua aplicação [referia-se à máquina a vapor, de Watt], não só aos moinhos mas a todo e qualquer uso, é inteiramente desconhecida em Portugal». Após aludir a algumas tentativas falhadas (no Arsenal Real da Fundição e nas Minas de Carvão de Pedra, em Buarcos - Figueira da Foz), acrescenta: «Parece que o influxo de alguma má estrela se opõe constantemente aos nossos progressos nas Artes! ${ }^{2}$.

Pouco depois (1820-1821), a máquina a vapor, aplicada à indústria, viria a ser, finalmente, introduzida em Portugal (Lisboa, região de Alcântara), curiosamente através de ex-emigrantes portugueses no Brasil ${ }^{3}$.

Em certo sentido, pode dizer-se que o mesmo J. Acúrsio das Neves - um dos casos mais interessantes de contradição ideológica, pois era conservador em política, como adepto convicto do absolutismo miguelista, e progressista em economia política - foi também o «pai» da história empresarial portuguesa. Com efeito, enquanto as questões agrárias, de acordo com os ideais fisiocráticos então em voga, monopolizavam a atenção da maior parte dos estudiosos do seu tempo, Acúrsio das Neves preocupava-se com as «artes» (indústria) e respectivo desenvolvimento e com a história dos estabelecimentos 
dedicados àquelas. Entre vários outros trabalhos sobre a matéria, destaca-se, para o tema que aqui nos interessa, aquele que dedicou à Real Fábrica do Rato, em Lisboa $(1827)^{4}$, no qual revela uma extraordinária perspicácia e apurada sensibilidade, acerca do papel e da relevância da história empresarial. A propósito, sublinhava Acúrsio das Neves, há mais de século e meio (em 1827, como já se indicou):

«Uma História completa dos nossos estabelecimentos fabris, acompanhada das competentes aplicações dos princípios da Economia Política e da Administração Fiscal, seria um importante serviço feito ao Estado, tanto pela novidade e dificuldade da matéria, que os nossos antecessores deixaram intacta e confundida, como pelos muitos auxílios que dela podemos tirar». E, ainda fiel à conhecida concepção da «história, mestra da vida», acrescenta: «Do passado se tiram sempre as melhores lições para se regular o futuro, e nesta História acharia o Governo os necessários conhecimentos para o seu bom acerto nos actos legislativos e administrativos em tais assuntos, seguindo a marcha dos que o precederam, no que acertaram, e desviando-se dela no que erraram. Os particulares achariam também os exemplos e ditames mais seguros que lhes servissem de guia nas suas empresas» ${ }^{5}$. O autor, além da história da Real Fábrica do Rato, fornece ainda elementos diversos acerca da história de várias «fábricas anexas» - que dependiam, administrativamente, daquela -, indicando qual era o seu objectivo: «juntar memórias, para que se não percam, e materiais de que alguma pena mais feliz do que a minha se possa aproveitar para escrever a história dos nossos estabelecimentos de indústria; e tive por melhor não sacrificar a utilidade à beleza. Fique embora um armazém de factos em que não reine a melhor ordem, cada um aproveitará dele o que lhe agradar e desprezará o resto» ${ }^{6}$.

A história de empresa feita por Acúrsio das Neves, embora desse especial relevância aos aspectos relacionados com as respectivas administrações - o que, aliás, ainda viria a suceder com outras histórias de empresa, já mesmo no século XX -, também apresenta observações importantes sobre tecnologia, preços, qualidade dos produtos, produção/escoamento dos artigos e, inclusive, até sobre a própria moda. Aludindo à burocracia e ao tempo gasto na produção, a partir da entrega de amostras, declara: «Passam [as amostras] para os inspectores, destes para os debuxadores, voltam aos primeiros, consulta-se a que mestres hajam de entregar-se, estes fogem-lhe com o corpo, porque lhes faz mais conta trabalharem nas antigas armações dos teares do que nos novos que trazem despesas, ninguém tem pressa, e quando chega a armar-se o tear e executar-se a obra tem passado a moda ${ }^{7}$.

Ao longo do século XIX, pouco temos sobre história empresarial propriamente dita. Alguns dos investigadores do fenómeno industrial - entre outros, João Andrade Corvo, Joaquim Henriques Fradesso da Silveira, Manuel Nunes Geraldes, Oliveira Martins, José Queirós e Sousa Viterbo - preferiam debru- 
çar-se sobre certas actividades industriais, a questão do proteccionismo ou mesmo a tecnologia, do que sobre os estabelecimentos artesanais ou fabris. Contudo, nos seus trabalhos, nos diversos relatórios sobre exposições internacionais ou universais ou ainda nos diversos volumes dos Inquéritos industriais, de 1881 e 1890 , encontram-se dados imprescindíveis para a história empresarial da segunda metade do século XIX e dos inícios do século XX. Por exemplo, José Queirós, na sua notável obra intitulada Cerâmica portuguesa (1. a ed., 1906), apresenta histórias sucintas de numerosas oficinas e fábricas de cerâmica, particularmente artística ${ }^{8}$.

Passados alguns anos, duas outras obras vieram a lume: Ateneu Comercial do Porto. 1869-1919, no 50. aniversário da sua fundação 9 ; Bento Carqueja, $O$ Commercio do Porto. Notas para a sua história ${ }^{10}$. No prefácio, o autor desta última revela a ligação afectiva que a ela tinha e, bem assim, os laços de família patentes na respectiva cultura de empresa. Com efeito, afirma Bento Carqueja (jornalista e autor de várias obras, nas quais foca sobretudo temas de índole económica e social):

«Apesar dos seus defeitos, é de todos os meus livros aquele a que fico tendo mais amor, porque define a melhor parte da minha existência, encerra doces recordações da minha vida, evoca saudades e gratas lembranças de pessoas e de factos que alentam a melhor parte da minha alma [...]. Morrerei contente [nascera em 1860 e viria a falecer em 1935], se conseguir deixar a grande obra jornalística, por mim herdada, tão pura nos seus processos, tão alevantada nas suas aspirações, tão vinculada ao bem da minha Pátria como a recebi dos seus fundadores e como tenho procurado conservá-la - QUERIDA JÓIA DE FAMÍLIA!»"

\section{O CENTENÁRIO DA VISTA ALEGRE}

Além dos tipos de história anteriormente mencionados, poder-se-ia também falar de uma «história comemoracionista». Esta será a que se faz a pretexto ou com o intuito de comemorar determinados eventos, geralmente coroados de êxito ou, pelo menos, de recordação agradável. Quanto ao desagradável - derrotas militares ou diplomáticas, catástrofes, etc. -, há uma certa tendência para o seu esquecimento, quer por parte do indivíduo, quer da sociedade, quer ainda da própria história.

A dita história, muito ligada a comemorações, embora criticada por diversos autores, não deixa de apresentar também alguns aspectos positivos. É que, como tem dado origem a uma abundante produção historiográfica, parte dela é de bom nível, embora uma outra parte se apresente pouco crítica e demasiado laudatória. Como é sabido, um número considerável de histórias de 
empresas nasceu, exactamente, a propósito da comemoração de datas marcantes para as organizações. Vem isto a propósito da Vista Alegre, empresa do ramo da porcelana, localizada em Ílhavo (distrito de Aveiro), já com uma longa história, de considerável sucesso. Fundada em 1824, por José Ferreira Pinto Basto (1774-1839), começou por produzir vidro até que, nos anos 30 do século passado, introduziu o fabrico da porcelana em Portugal. Alcançou grande prestígio, em Portugal e no estrangeiro, estando os produtos, com a marca «VA», presentes em numerosas lojas e museus célebres, de vários países.

Ao fim de um século de laboração (1824-1924), foi decidido comemorar condignamente o evento, tendo sido então ampliadas e remodeladas as instalações, remodelado o Museu e publicada a sua história. Quanto ao penúltimo aspecto indicado, também a Vista Alegre foi pioneira, dando o primeiro passo significativo para a criação da museologia de empresa em Portugal, havendo hoje, no País, cerca de uma dúzia de Museus de empresa e, inclusive, uma associação (APOREM - Associação Portuguesa de Empresas com Museu).

Acerca da história, foi então publicada a importante obra, intitulada $A F a ́$ brica da Vista Alegre. O Livro do seu Centenário. 1824-1924, bem como A Fábrica da Vista Alegre. Apêndice ao Livro de seu Centenário. 1824-1924 (em volume separado) e, ainda, Vista Alegre. Catálogo da Exposição. 1824-1924.

Deve acrescentar-se que, mesmo anteriormente, já a história da empresa havia despertado a curiosidade de alguns investigadores. Assim sucedeu com P. W. de Brito Aranha - que lhe dedicou um capítulo das suas Memórias Histórico-Estatísticas (1871) ${ }^{12}$ e com o erudito aveirense, J. A. Marques Gomes, que sobre ela elaborou A Vista Alegre - Apontamentos para a sua história $(1883)^{13}$.

Todavia, o projecto de 1924 foi bastante mais ousado, quer do ponto de vista da investigação - arquivística e de fontes materiais, com relevo para os aspectos artísticos -, quer quanto aos respectivos colaboradores. É que, além do administrador e descendente do fundador, João Teodoro Ferreira Pinto Basto, profundo conhecedor da indústria cerâmica, foi possível obter a colaboração do poeta Afonso Lopes Vieira e, no Apêndice e no Catálogo - acima referidos - e, na organização de uma exposição, também a de investigadores e artistas de grande mérito, entre os quais, José de Figueiredo, Joaquim de Vasconcelos, António Teixeira Lopes, José Pessanha e Reinaldo dos Santos. A abrir a referida História, a Sociedade de Porcelana da Vista Alegre, Lda. dava a seguinte explicação acerca dos objectivos a alcançar:

«Esta publicação não tem qualquer pretensão a trabalho literário, histórico ou técnico. É apenas uma obra de divulgação do que tem sido e do que é a VISTA ALEGRE. Este estabelecimento industrial, funcionando há 100 anos, já vai tendo uma história, e das várias notícias que a seu respeito se têm publicado, que nos propusemos compilar este trabalho. É mais do que tudo uma 
consagração e uma homenagem à memória do seu ilustre Fundador, José Ferreira Pinto Basto, prestada pelos seus descendentes na data em que a Fábrica completa o seu centenário». E, acerca de uma cultura de empresa, marcadamente familiar - característica que ainda é visível actualmente, não obstante todas as transformações operadas e de a Vista Alegre se ter associado a um grande grupo internacional, produtor de cerâmica -, sublinha-se:

«Orgulham-se esses descendentes de ter conservado na posse da família, e de ter mantido em laboração ininterruptamente durante um século, o estabelecimento fabril que o seu antepassado com tanto entusiasmo fundou» ${ }^{14}$.

Como se deduz do que se acaba de expor, a Vista Alegre mantinha-se - e permanece - muito ligada ao seu fundador, grande capitão de indústria e líder carismático, no sentido que à expressão é dado por Max Weber.

Acerca dos objectivos enunciados, convirá acrescentar que a referida história, a despeito do relevo atribuído, obviamente, ao fundador e aos administradores que lhe sucederam, fornece um bom contributo para o estudo de aspectos que ultrapassam a própria organização: indústrias de cerâmica, de porcelana e do vidro, habitações e instituições operárias, história local de Ílhavo, etc.

\section{A HISTÓRIA EMPRESARIAL FEITA A PARTIR DE DENTRO}

Pelo menos nas décadas imediatas, o exemplo da Vista Alegre não foi seguido, já que a história empresarial, nos anos imediatos, pouco interesse despertou. Com a queda da República/instauração da Ditadura Militar (1926) e a institucionalização do Estado Novo (1932-33), a historiografia portuguesa manteve-se, em grande parte, fechada às inovações, privilegiando os aspectos político-militares, a biografia dos heróis, os factos e a cronologia. Salvo raras excepções, tratava-se de uma «história de regime», bastante comprometida ideologicamente, na qual a história empresarial não tinha lugar. $\mathrm{O}$ mesmo sucedia, embora por motivos diversos, na própria história local, feita geralmente por amadores, eruditos que conheciam bem a realidade e as proprias fontes, mas desactualizados quanto a metodologia e a concepções historiográficas. Para eles, a empresa não se revestia de «dignidade» suficiente para ser objecto de investigação histórica.

Entretanto, na década de 50, começam a surgir alguns trabalhos que merecem ser referenciados. Refiro-me a:

- Manuel Ayres Falcão Machado, Fábrica de cerâmica Estrela de Alva. Meio século ao serviço da economia nacional (1904-1954), $1954^{15}$.

- J. Silva Carvalho, A Ferraria da Foz do Alge, 1953-1957 ${ }^{16}$. 
No primeiro caso, trata-se da história sucinta de uma empresa de cerâmica de construção, das muitas que se instalaram em Portugal, nas últimas décadas do século XIX e primeiras do século XX. O autor, dedicado à «história divulgação», sobretudo local, fez esta incursão pela história empresarial, elaborando um trabalho com algum interesse, mas sucinto e denotando o uso de metodologia pouco actualizada.

Por seu turno, J. Silva Carvalho, engenheiro, estudou a importante Ferraria da Foz do Alge - de relevância significativa, em Portugal, nos finais do século XVIII e primeiras décadas do XIX (até 1834) -, dando relevo não só às administrações que a dirigiram, como também aos aspectos tecnológicos. De modo ainda pouco habitual na investigação histórica, entre nós, o autor utilizou abundantemente fontes materiais (tendo-se revelado, em certa medida, um pioneiro da arqueologia industrial), para o que, por certo, contribuiu a sua formação académica e profissional, como engenheiro do Serviço de Fomento Mineiro.

No final dos anos 60 , assinalando a passagem do $2 .^{\circ}$ Centenário da instalação da Real Fábrica de vidros da Marinha Grande, foi publicada a obra de Carlos Vitorino da Silva Barros, Real Fábrica de Vidros da Marinha Grande. Il centenário, $1769-1969^{17}$.

No que concerne à Banca, registou-se igualmente uma certa produção historiográfica, ainda que de valor e nível diversificado. Estamos aqui perante casos típicos daquela que designo por «história empresarial a partir de dentro», em dois sentidos. Em primeiro lugar, porque a iniciativa de fazer a respectiva história parte da própria instituição e é, por esta, controlada. Em segundo lugar, porque a tarefa é atribuída a funcionário(s) do próprio banco, com os prós e os contras inerentes a tal situação. Com efeito, não se tratando, regra geral, de historiadores, podem conhecer as fontes e a própria realidade institucional coeva, mas nem sempre dominam a metodologia da ciência histórica. Vejamos alguns exemplos.

A Assembleia Geral do então Banco Lisboa \& Açores (fundado em 1875) aprovou uma proposta, em 11 de Fevereiro de 1939, segundo a qual mandaria publicar «a História do Banco Lisboa \& Açores, desde a sua fundação até 1939, encarregando a Direç̧ão, com esse fim, o funcionário do Banco que julgue mais apto para essa missão». E que tipo de história se desejava fazer? Na mesma proposta pode ler-se:

«A História do Banco Lisboa \& Açores obedecerá a um critério rigorosamente científico de história económica, no seu aspecto económico e financeiro, e constará da descrição minuciosa de todos os factos da vida do Banco que interessarem ao seu desenvolvimento, influência na vida portuguesa, com exclusão daqueles que constituem segredo profissional, sendo acompanhada de gráficos e gravuras, bem como das biografias dos indivíduos que formaram os corpos gerentes» ${ }^{18}$. 
É interessante a alusão, na proposta, a «um critério rigorosamente científico de história económica ...», ao que não terá sido estranho o seu subscritor, o accionista Manuel Busquets de Aguilar, ele próprio autor de uma obra de investigação histórica, sobre o Curso Superior de Letras de Lisboa ${ }^{19}$. A elaboração do referido trabalho foi atribuída ao «antigo e ilustrado funcionário do Banco, Sr. Luiz Torrezão Veiga da Cunha [...], coadjuvado, no que respeita aos gráficos, por outro hábil funcionário, o Sr. Mário de Macedo». Quanto ao respectivo "produto historiográfico», trata-se de pouco mais de 100 páginas, profusamente ilustradas, com fotografias, gráficos e reprodução de alguns documentos importantes. O livro encontra-se dividido em três partes: «Organização», «Os dirigentes» e «Os factos». Mais do que a análise histórica, predominam a descrição e a publicação de dados.

Por sua vez, também o na altura chamado Banco Totta-Aliança, na comemoração do seu $125 .^{\circ}$ aniversário (1843-1968), elaborou a sua história, de cuja dedicatória consta: «À memória das gerações que nos precederam neste Estabelecimento de Crédito no centésimo vigésimo quinto aniversário da sua fundação" ${ }^{20}$. Neste caso, nem sequer se sabe quem elaborou a história em análise, a qual, do ponto de vista metodológico, tem mais deficiências que a anterior. Essencialmente descritiva e factual, encontra-se estruturada por capítulos (seis, ao todo), mas estes são de índole meramente cronológica. Com ilustração mais pobre, apresenta, contudo, dois aspectos positivos dignos de serem sublinhados: notas bibliográficas e resumos da obra (no final), em francês e inglês, além de um anexo, com gráficos.

Esquema análogo foi seguido na história de $O$ Banco Lisboa \& Açores. 1875-1969, cujos capítulos são também de índole cronológica e apresenta, igualmente, «Notas bibliográficas». Não tem ilustração e o autor do texto (apenas indicado, discretamente, no final, na última folha e juntamente com a fícha técnica) foi João de Sousa da Câmara ${ }^{21}$.

Sensivelmente pela mesma altura, foi publicado um outro trabalho, misto de história de empresa e de biografia do fundador [Arthur Cupertino de Miranda], intitulada Banco Português do Atlântico - Uma vida, uma obra (dir. literária e iconográfica da escritora Agustina Bessa-Luís) ${ }^{22}$.

Este conjunto de histórias da banca culminou com uma obra monumental, intitulada Cem anos do Banco Nacional Ultramarino na vida portuguesa 1864-1964 ${ }^{23}$. A narração histórica e coordenação de documentos estiveram a cargo de Braga Paixão. Tendo feito o antigo Curso Superior de Letras, Vítor Manuel Braga Paixão (1892-1982), membro da Academia das Ciências de Lisboa e da Academia Portuguesa da História, além de professor liceal e de director do ensino primário, ocupou relevantes cargos administrativos no âmbito da educação colonial, até 1962, altura em que se aposentou como director-geral do ensino ultramarino. 
Através da obra acima indicada, além da história da instituição propriamente dita, interessava enaltecer a política colonial (oficialmente designada ultramarina) portuguesa, numa altura em que o país se debatia com guerra em várias colónias e com críticas a nível internacional - inclusive da ONU -, devido à manutenção dos territórios coloniais sob a sua alçada. Trata-se, assim, de uma história de empresa com objectivos mais amplos, em parte marcados por aspectos político-ideológicos. A propósito, escreveu Braga Paixão, na «Advertência preliminar»:

«Se na consciência de quem procedia aos estudos não houvesse já, concebidos e arreigados, argumentos que radicalmente atestavam ser indigna, além de falha de razões, a presente campanha contra Portugal, a própria reconstituição histórica de como nasceu o Banco Nacional Ultramarino e da cumprida intenção que orientou os seus Cem anos de vida, alinhava novos títulos de orgulho e de verdade para contrapor à depreciação odiosa a que se entregam os inimigos da Nação portuguesa» ${ }^{24}$.

\section{CONTRIBUTO DOS HISTORIADORES DE PROFISSÃO}

Sobretudo a partir dos anos 70 , começou a haver uma certa aproximação entre empresas/organizações e a comunidade dos historiadores. Algumas reservas ou reticências - de parte a parte - foram sendo eliminadas, embora de forma lenta e nem sempre fácil. Assim, em 1971 foi publicada a História do Banco de Portugal. 1821-1846 (vol. I), da autoria de Damião Peres (1889-1976). Trata-se de um prestigiado historiador, autor de uma vasta obra e que dirigiu uma História de Portugal (em 9 vols., cuja leitura é ainda de grande utilidade). A história do Banco de Portugal está a ser continuada por Jaime Reis, outro notável historiador, também com obra importante e introdutor, em Portugal, da New Economic History ${ }^{25}$.

Entretanto, mais recentemente, outros historiadores têm vindo a dar o seu contributo à história da banca, como, por exemplo, A. H. de Oliveira Marques (Banco Crédito Predial Português) ${ }^{26}$, Fernando de Sousa (Banco Borges \& Ir$m \tilde{a} o)^{27}$, Ana Bela Nunes, Carlos Bastien e Nuno Valério (Caixa Económica. Montepio Geral. 150 anos de história. 1844-1994) ${ }^{28}$ e eu próprio (a Banca na área de Coimbra) ${ }^{29}$.

Relativamente a companhias seguradoras, a história encontra-se praticamente por fazer, embora já possamos contar com a da Mundial Confiança. 1913-1988, elaborada, aquando da comemoração do seu $75 .^{\circ}$ aniversário, por Fernando Marques da Costa ${ }^{30}$.

No que respeita ao sector secundário, têm sido igualmente efectuadas histórias de algumas empresas pertencentes, entre outros, aos seguintes ramos: 
têxtil (Manuel da Silva Guimarães, História de uma Fábrica. A Real Fábrica de Fiação de Thomar ${ }^{31}$ ), vidro (José M. Amado Mendes, col. de Manuel Ferreira Rodrigues, Santos Barosa, 100 anos no vidro. 1889-1989 $9^{32}$; dos mesmos autores, Ricardo Gallo. Um século de tradição e inovação no vidro. 1899 -1999), metalomecânica (Manuel Ferreira Rodrigues, «A Metalurgia Casal, 1964-1974: Elementos para uma cultura de empresa» ${ }^{33}$ e Duarte Sampaio Loio, Companhia Portuguesa de Fornos Eléctricos. Subsídios para a sua história, 1917-1967 ${ }^{34}$.

Nos exemplos que acabam de ser referidos e noutros já concretizados ou em vias de concretização - vários dos quais foram dados a conhecer em Évora, no I Encontro sobre História Empresarial em Portugal (27-28 de Outubro de 1995) -, pode falar-se de história empresarial «feita de fora», isto é, por investigadores que, regra geral, não integram os quadros de pessoal das respectivas organizações. Além disso, trata-se, na maior parte dos casos, de indivíduos (historiadores, economistas, sociólogos, etc.) que fazem da pesquisa (e/ou da docência) a sua profissão. Embora, uma ou outra vez, possam ter um conhecimento mais limitado do funcionamento da respectiva organização, a actualização metodológica, por um lado, e o «afastamento» - dado que se encontram de fora -, por outro, colocam-nos em posição vantajosa, sendo-lhes mais fácil manterem-se dentro de critérios estritamente científicos.

Alguns contributos também têm sido dados por jornalistas, em revistas da área da Gestão/Economia (Exame, Executive Digest, Fortuna, Valor, etc.) ou mesmo em jornais ou respectivos suplementos de Economia (Expresso e $P \hat{u}$ blico, por exemplo). Porém, trata-se, geralmente, de breves sínteses, do género das que constam da obra sob o título História das Empresas (Lisboa, Nova Nórdica/Tempo, 1988), úteis sobretudo como sugestões para posterior investigação, mais desenvolvida.

\section{UMA «NOVA» HISTÓRIA EMPRESARIAL EM CONSTRUÇÃO?}

Face ao que, sucintamente, acabei de expor, julgo que, efectivamente, se poderá falar dos alicerces de uma nova história empresarial, em Portugal, que têm vindo a ser lançados, sobretudo nas últimas décadas. À luz da nova metodologia histórica, não se pretende glorificar organizações, nem tão-pouco esclarecer apenas os pontos altos da sua história, mas sim investigar, compreender e divulgar o seu passado, nas suas múltiplas vertentes e nos diversos momentos, bons ou maus. A história não é feita só de sucessos, sendo o estudo dos insucessos e das crises tão ou mais esclarecedores e elucidativos que o daqueles. Assim, uma nova história de empresa, que se quer científica, não pode deixar de contemplar, por exemplo: os recursos humanos e os recursos materi- 
ais; a tecnologia, sua evolução, transferência e adaptação; a sociedade e a cultura envolvente; a política e a ideologia.

Quanto aos recursos humanos, há que estudar - recorrendo à biografia e à prosopografia - empresários e gestores (sem esquecer as diversas modalidades de gestão), técnicos e operários, pois todos eles são imprescindiveis às organizações. Devem estudar-se os indivíduos, e não só as massas, pois, como afirmou W. Sombart, em L'apologie du capitalisme $e^{35}$, são eles as verdadeiras «forças motrizes». Sublinha, pois, o autor: «Esta força motriz, podemos dizê-lo desde já, não é outra senão o homem vivo, com as suas aspirações, as suas finalidades, os seus impulsos voluntários; o homem vivo, com o seu pensamento e as suas paixões».

Acerca da tecnologia, além da sua evolução, torna-se necessário investigar a transferência e adaptação a novos contextos, assim como o papel da inovação, na linha dos estudos de Schumpeter ${ }^{36}$. A sociedade e a cultura condicionam, obviamente, a história das organizações. Daí que a pesquisa histórica tenha que debruçar-se, também, sobre aquelas. As diferenças culturais na gestão, estudadas por Daniel Bollinger e Geert Hofstede ${ }^{37}$, não surgiram do nada nem são de formação recente, mas têm uma história, que é necessário investigar. Por sua vez, a política - como o papel do Estado e seus agentes - e a própria ideologia devem também merecer a atenção, de quem se dedique à história empresarial. Por exemplo, uma ideologia imbuída de nacionalismo, na qual os objectivos da empresa e os objectivos do próprio país frequentemente andam associados - recorde-se a cultura de empresa japonesa -, pode funcionar como um importante factor de motivação para as pessoas, no desempenho das suas actividades profissionais nas organizações.

O historiador de empresa também não poderá esquecer a função que o quotidiano tem vindo a assumir na história. Como já foi destacado, por um dos autores anteriormente referidos, «A história de qualquer empresa, para além da narrativa dos sucessos [ao que eu acrescentaria, e dos proprios insucessos] empresariais, é também, devia de ser, a história do quotidiano das relações e dos ritmos de trabalho que nela existiram. Esta é a reconstituição mais difícil, quando não impossível» ${ }^{38}$.

Metodologicamente, a questão das fontes desempenha um papel relevante. Em virtude da frequente escassez de documentação nos arquivos de grande número de empresas, facto a que aludem alguns dos autores citados - A. H. de Oliveira Marques e F. Marques da Costa -, há que recorrer a tipos de fontes diversificadas: orais e iconográficas, materiais e de arquivos privados, imprensa coeva, arquivos de outras empresas/organizações, etc. Lembro o manancial de informação que, sob este ponto de vista, pode ser fornecido pelos arquivos das companhias de seguros.

Por último - para não me alongar demasiado -, deve recorrer-se à interdisciplinaridade, ao fazer-se história empresarial. $\mathrm{O}$ historiador pode, pois, re- 
ceber excelente ajuda de especialistas noutras áreas (sociologia, arquitectura, engenharia, arqueologia industrial, economia, etc.), pelo que hoje não há disciplinas independentes, mas sim complementares ou colaboradoras.

Naturalmente que, para que a «nova» história empresarial se desenvolva, torna-se necessário que o trabalho de campo - ou a investigação empírica seja acompanhada por estudos de índole teórica e metodológica. Só assim se poderão estreitar as relações entre empresa e história, dado que elas necessitam uma da outra. Como já tive o ensejo de afirmar noutro trabalho - intitulado $A$ história na empresa e a empresa na história -, «a empresa não se limita a ser tributária da história. Pelo contrário, aquela pode funcionar como uma espécie de «laboratório» - particularmente significativo, numa altura em que, aos case-studies, se atribui tanta relevância -, ao qual se poderá recorrer em múltiplas circunstâncias» ${ }^{39}$. Sobre a relação história-empresa, também já foi sublinhado por Pedro Fraile: «A partir dos anos 1960 a disciplina [história de empresa] mudou a sua ênfase e enfoque de uma perspectiva da "história de empresa" para outra das "empresas na história". Segundo as palavras de Chandler, a História Económica da Empresa deixou de ser história descritiva de casos específicos e começou a ser história institucional comparada, com capacidade para gerar "conceitos e generalizações não históricos". Apesar de tudo - prossegue P. Fraile - esta transição não foi fácil. A insatisfação com o sistema de casos de empresas levou a que os historiadores económicos da empresa procurassem ajuda noutras ciências sociais» ${ }^{40}$.

Outras transformações da história de empresa, a longo prazo, foram analisadas por John F. Wilson, na sua importante obra, intitulada British Business History. 1720-1994 $4^{41}$. Entre muitos outros exemplos que se poderiam referir, recorde-se que dificilmente se poderá fazer o balanço de determinada política económica, sem se ter em consideração os seus efeitos a nível das empresas estudadas, através das respectivas histórias. Trata-se, afinal, da óbvia complementaridade entre o macroeconómico e o microeconómico ${ }^{42}$.

\section{NOTAS}

\footnotetext{
* O tema do trabalho que ora se publica, ampliado e anotado, inicialmente apresentado às XV Jornadas de História Económica (Tandil-Argentina, 9-11 de Outubro de 1996), foi também focado na oração de sapiência proferida no Instituto Superior de Ciências da Informação e da Administração (ISCIA), em Aveiro, por ocasião da abertura solene do ano lectivo, em 13 de Novembro de 1996.

${ }^{1}$ Gertrude Himmelfarb, 1987, p. 4. Referência completa à obra desta autora - como às dos autores indicados nas notas seguintes - encontra-se no final, deste artigo, na Bibliografia.
} 
${ }^{2}$ José Acúrsio das Neves, s.d., vol. 4, p. 525; José M. Amado Mendes, «Cabo Mondego (Figueira da Foz): Exploração mineira e indústria», Arqueologia Industrial, $3^{a}$ série, vol. II, $\mathrm{n}^{\circ}$ 1-2, 1998, p. 5-21.

${ }^{3}$ José M. Amado Mendes, 1985, p. 23-32.

${ }_{5}^{4}$ J. Acúrsio das Neves, op. cit., p. 143-320.

${ }^{5}$ Idem, op. cit., p. 145.

${ }^{6}$ Idem, op. cit., p. 146.

${ }^{7}$ Idem, op. cit., p. 64.

${ }^{8}$ José Queirós, 1987. Ver a minha recensão a esta obra, 1991, p. 191-198.

${ }^{9}$ Porto, 1919.

${ }^{10}$ Porto, 1924.

${ }^{11}$ Idem, op. cit., p. 7-8.

${ }^{12}$ P. W. de Brito Aranha, 1871, p. 293-233.

${ }^{13}$ J. A. Marques Gomes, 1883 (reeditada em 1993). Recentemente, novo contributo foi dado à história da Vista Alegre, com a publicação da seguinte obra: Ilda Arez et al., 1990.

${ }^{14}$ João Teodoro Ferreira Pinto Basto (ed. dir. por Afonso Lopes Vieira), 1924, p. 9.

${ }^{15}$ Publicado em Coimbra, 1954.

${ }^{16}$ Publicado em Estudos, Notas e Trabalhos do Serviço de Fomento Mineiro, vols. VIII-XXIII, 1953-1957.

${ }^{17}$ Lisboa, 1969.

${ }^{18}$ Banco Lisboa \& Açores [...], 1940, p. 5.

${ }^{19}$ M. Busquets de Aguilar, 1939.

${ }^{20}$ Lisboa, 1968.

${ }^{21}$ Lisboa, 1972.

${ }^{22}$ Porto, 1969.

${ }^{23} 4$ vols., Lisboa, 1964.

${ }^{24}$ Cem anos do Banco Nacional Ultramarino na vida portuguesa. 1864-1964, vol. I, 1994, p. XII.

25 Jaime Reis, 1993; 1996.

${ }^{26}$ A. H. Oliveira Marques (col. de Jorge Ramos do Ó e Sérgio Bustorff Fortunato), 1988.

${ }^{27}$ Fernando de Sousa, 1984. A este autor se deve também a história de um conhecido periódico português: Fernando de Sousa, Jornal de Notícias [...], 1988.

${ }^{28}$ Ana Bela Nunes, Carlos Bastien e Nuno Valério, 1994;

${ }^{29}$ José M. Amado Mendes, 1984, p. 335-384.

${ }^{30}$ Lisboa, 198 .

${ }^{31}$ Santarém, 1976. V. minha recensão, 1977, p. 351-358.

${ }^{32}$ Marinha Grande, 1991.

${ }^{33}$ Gestão e Desenvolvimento, n. ${ }^{\circ} 3,1994$, p. 103-151.

${ }^{34}$ Nelas, 1994.

${ }^{35}$ Werner Sombart, 1932, t. I, p. 27.

${ }^{36}$ V. José Amado Mendes, 1995, p. 41-57.

${ }^{37}$ Daniel Bollinger et Geert Hofstede, 1987.

${ }^{38}$ F. Marques da Costa, op. cit., p. 5.

${ }^{39}$ José M. Amado Mendes, 1992, p. 433-443.

${ }^{40}$ Pedro Fraile, 1994, p. 44.

${ }^{41}$ Manchester University Press, 1995.

${ }^{42}$ Após a elaboração do presente texto, a temática em epígrafe foi também objecto de análise por Carlos Bastien, no âmbito das suas Provas de Agregação, no Instituto Superior de Economia e Gestão (ISEG), em Lisboa (Carlos Bastien, 1996). 


\section{BIBLIOGRAFIA}

AGUILAR, Manuel Busquets de (1939), O Curso Superior de Letras (1858-1911), Lisboa.

ARANHA, P. W. de Brito (1871), Memorias historicoestatisticas de algumas vilas e povoações de Portugal, Lisboa, Livraria de A.A. Pereira - Editor, p. 293-233.

ATENEU (1919), Comercial do Porto. 1869-1919, no 50. aniversário da sua fundação, Porto, ed. Comemorativa.

Banco Lisboa \& Açores. Elementos para a sua história (texto de Luiz Torrezão Veiga da Cunha e Mário de Macedo), (1940), Lisboa, Casa Portuguesa.

Banco Português do Atlântico. Uma vida, uma obra (dir. literária e iconográfica da escritora Agustina Bessa-Luís), (1969), Porto.

Banco (O) Totta-Aliança, (1968), Lisboa.

BASTIEN, Carlos (1996), História Empresarial - I. Relatório científico-pedagógico apresentado no âmbito das provas de agregação, Lisboa, ISEG (Trabalho mimeografado).

BASTIEN, Carlos (1996), Temas e problemas de História Empresarial. Lição-síntese apresentada no âmbito das provas de agregação, Lisboa, ISEG. Trabalho mimeografado.

BASTO, João Teodoro Ferreira Pinto (ed. dir. por Afonso Lopes Vieira) (1924), A Fábrica da Vista Alegre. O Livro do seu centenário. 1824-1924, Lisboa, Vista Alegre.

BOLLINGER, Daniel e HOFSTEDE, Geert (1987), Les différences culturelles dans le management, Paris, Les Ed. d'Organisation.

CÂmARA, João de Sousa da (1972), O Banco Lisboa \& Açores 1875-1969, Lisboa.

Carqueja, Bento, (1924), O Commercio do Porto. Notas para a sua história, Porto.

Carvalho, J. Silva (1953-1957), «A Ferraria da Foz do Alge», 1953-1957, in Estudos, Notas e Trabalhos do Serviço de Fomento Mineiro, vols. VIII-XXIII.

Costa, F. Marques da (1989), Mundial Confiança. 1913-1988, Lisboa.

FRAILE, Pedro (1994), «La historia economica de la empresa como disciplina independente: una perspectiva historica», Juan Hernandez Andreu e José Luis García Ruiz (compiladores), Lectures de Historia, Manchester University Press, 1995. Empresarial, Madrid, Ed. Civitas.

GOMES, J. A. Marques (1993), A Vista Alegre - Apontamentos para a sua história, Porto, (reeditada, em fac-símile, sob o título A Vista Alegre. Memória histórica, Aveiro, Estante Editora).

Guimarães, Manuel da Silva (1976), História de uma Fábrica. A Real Fábrica de Fiação de Thomar, Santarém (Ver a recensão que fiz a esta obra, Revista Portuguesa de História, t. XVII, p. 351-358).

HimmelfaRB, Gertrude (1987), The New History and the Old. Critical Essays and reappraisals, The Belknap Press of Harvard University Press, p. 4. 
LoIO, Duarte Sampaio (1994), Companhia Portuguesa de Fornos Eléctricos. Subsídios para a sua história, 1917-1967, Nelas.

MACEDO, J. Borges de (1990), «Introdução», Ilda Arez et al., Vista Alegre. Porcelanas. de Lisboa, Ed. INAPA.

MaCHAdO, Manuel Ayres Falcão (1954), Fábrica de cerâmica Estrela de Alva. Meio século ao serviço da economia nacional (1904-1954), Coimbra, Tip. Comercial.

MARQues, A. H. Oliveira (col. de Jorge Ramos do Ó e Sérgio Bustorff Fortunato) (1988), Companhia de Crédito Predial Português. 125 anos de História, Lisboa, Banco Crédito Predial Português.

MEndes, José M. Amado (1984), A área económica de Coimbra. Estrutura e desenvolvimento industrial, Coimbra, Comissão de Coordenação da Região Centro.

MEndes, José M. Amado (1985), «A indústria portuguesa no século XIX», Prelo, n. ${ }^{\circ}$, p. 23-32.

MENDES, José M. Amado (col. Manuel Ferreira Rodrigues) (1991), Santos Barosa, 100 anos no vidro. 1889-1989, Marinha Grande, Santos Barosa - Vidros, S.A..

Mendes, José M. Amado (1991), «Recensão», na Revista Portuguesa de História, t. XXVI, p. 191-198.

Mendes, José M. Amado (1992), «A história na empresa e a empresa na história», Estudos de homenagem a Jorge Borges de Macedo, Lisboa, INIC, p. 433-443.

MENDES, José M. Amado (1995), «Sucesso e inovação no mundo empresarial: Perspectiva histớrica», Gestão e Desenvolvimento, n. ${ }^{\circ} 4$, p. 41-57.

MENDES, José M. Amado (1998), «Cabo Mondego (Figueira da Foz): Exploração mineira e indústria», Arqueologia Industrial, $3^{\mathrm{a}}$ série, vol. II, $\mathrm{n}^{\mathrm{o}}$ 1-2, 1998, p. 5-21.

MENDES, José M. Amado e RODRIGUES, Manuel Ferreira (1999), A Ricardo Gallo. Um século de tradição e inovação no vidro, 1899-1999, Marinha Grande, Ricardo Gallo S. A.

Neves, José Acúrsio das (s. d.), Obras completas, vol. 4: Memória Económico-Política sobre a liberdade do comércio dos grãos com a sua aplicação às Ilhas dos Açores e outros escritos económicos, Porto, Ed. Afrontamento.

PAIXÃo, Braga (Narração histórica e coordenação de documentos) (1964), Cem anos do Banco Nacional Ultramarino na vida portuguesa. 1864-1964, 4 vols., Lisboa, Banco Nacional Ultramarino.

QuEIRós, José (1987), Cerâmica portuguesa e outros estudos (org., apresentação, notas e adenda iconográfica de José Manuel Garcia e Orlando da Rocha Pinto), Lisboa, Ed. Presença.

REIS, Jaime (1993), O atraso económico português. 1850-1930, Lisboa, Imprensa Nacional-Casa da Moeda.

REIS, Jaime (1996), O Banco de Portugal. Das origens a 1914, I vol., Lisboa, Banco de Portugal.

RODRIGUES, Manuel Ferreira (1994), «A Metalurgia Casal, 1964-1974. Elementos para uma cultura de empresa», Gestão e Desenvolvimento, n. ${ }^{\circ} 3$, p. 103-151.

SOMBART, Werner (1932), L'apologie du capitalisme (trad. do alemão), t. I, Paris, Payot. 
SousA, Fernando de (1984), Banco Borges \& Irmão. 1884-1984. Uma instituição centenária, Porto, Banco Borges \& Irmão.

SouSA, Fernando de (1988), Jornal de Notícias. A memória de um século (1888-1988), Porto, Jornal de Notícias.

WILSON, John F. (1995), British Business History. 1720-1994, Manchester University Press. 